\title{
Avaliação histoquímica de processos degenerativos tendinosos, ligamentares e de cartilagem articular de equinos
}

Grasiela de Bastiani", Flávio De La Côrte, Karin Érica Brass, Camila Cantarelli, Stefano Leite Dau, Taiara Müller da Silva, Gláucia

Denise Kommers

Universidade Federal de Santa Maria (UFSM), Santa Maria, RS, Brasil

*Autor correspondente

e-mail: grasibage@hotmail.com

\section{Resumo}

O processo reparativo de tendões e ligamentos é composto por diferentes fases como inflamação, neovascularização, proliferação, granulação e fibrose tecidual. 0 objetivo do presente estudo foi caracterizar a diferenciação do colágeno tipo I em colágeno tipo III e a presença de tecido conjuntivo no processo de reparação tendinosa e ligamentosa por meio de colorações especiais. Processos degenerativos cartilaginosos são descritos pela fibrilação e eburnação da cartilagem articular, mas demonstra-se que a regeneração da mesma não ocorre devido à perda de suas camadas e de sua matriz proteoglicana. Após avaliação ultrassonográfica da articulação metacarpofalangeana de 37 membros torácicos equinos, amostras de tendões, ligamentos e cartilagem articular anormais foram dissecadas para estudo anatomopatológico. Alterações como ecogenicidade, forma, tamanho, arquitetura, cor e achados histológicos como fibroplasia, colagenólise, metaplasia cartilaginosa em tendões e ligamentos, fibrilação e eburnação de cartilagem articular foram critérios de seleção das estruturas para a elaboração das colorações especiais. Técnicas histoquímicas, como Tricrômico de Masson (TM), Picrosírius Red (PR) e Alcian Blue (AB), foram aplicadas em espécimes de tendão flexor digital profundo $(n=5)$, de tendão flexor digital superficial $(n=3)$, ligamento suspensório ( $n=1)$, ligamento anular palmar $(n=2)$, ligamentos colaterais medial e lateral $(n=2)$, cartilagem articular $(n=6)$. Observou-se alterações nos tendões e ligamentos, que variaram de fibroplasia, colagenólise, infiltrados linfohistioplasmocítico e metaplasia cartilaginosa. Na histoquímica, estas alterações correspondem ao acúmulo de tecido conjuntivo corado em azul (TM), a predominância de colágeno tipo III corado em verde claro devido a sua birrefringência (PR) associado à perda de paralelismo das fibras colágenas. A Técnica de Alcian Blue em cartilagens articulares demonstra uma coloração que varia de um azul extremamente claro em porções onde se evidencia a fibrilação até a exposição do osso subcondral. Esta baixa marcação do 
$\mathrm{AB}$ pode estar associada à perda de matriz proteoglicana. A deposição de tecido conjuntivo cicatricial em tendões e ligamentos pode ser identificada pelo TM, que se expressa em uma marcação em azul. Porém, as fibras colágenas não podem ser distinguidas através desta técnica. Em contrapartida, a técnica de PR contribui para a diferenciação de colágeno tipo I (variação de vermelho a laranja) e tipo III (variação de verde claro a escuro) devido ao reforço de birrefringência, ao paralelismo das fibras colágenas tendinosas e ao arranjo em onda das fibras ligamentares. A utilização destas técnicas de histoquímica demonstra que fibroplasia, colagenólise e metaplasia cartilaginosa de tendões e ligamentos também são caracterizadas pela deposição de tecido conjuntivo, presença de grande quantidade de colágeno tipo III e perda de paralelismo das fibras colágenas. Foi verificado também que, em processos de degenerações cartilaginosas onde ocorre a perda das camadas articulares, consequentemente também se observa a marcação decrescente da matriz proteoglicana.

Palavras-chave: Histoquímica. Tendões. Ligamentos. 